\title{
The Impact of Substrate Materials to the Design of UWB Modern Antennas
}

\author{
Gerard Rushingabigwi, Liguo Sun*, Yuxing He, Mengying Zhu, Yongjie Li, \\ Jean de Dieu Ntawangaheza \\ Department of Electronic Engineering and Information Science, Applied Electromagnetic Fields Group, \\ University of Science and Technology of China (USTC), Hefei, China \\ Email: "gerard@mail.ustc.edu.cn, liguos@ustc.edu.cn
}

Received 30 December 2015; accepted 26 February 2016; 2 March 2016

\begin{abstract}
The theory of microstrip antennas has motivated us to design a highly improved gain antenna under this category. It is a microstrip monopole antenna characterized by omni-directional radiation as well as a high radiation gain. A review of different methodologies to designing antennas with broad/ultra-wide band performance for various applications is enriched by our original antenna design. This is an original model analyzed over different substrate materials and finally optimized for the bandwidth of $(3.3-5.8) \mathrm{GHz}$ just below $-10 \mathrm{~dB}$ of return loss (RL). The antenna is judged for high gain when the ground plane size is reduced to nearly half that of substrate. The impact of the substrate materials is discussed in this article. The master design tool is Ansoft High Frequency Simulator Structure (HFSS), one of Finite Element Method (FEM) based software tools. The antenna would be printed on a $1.524 \mathrm{~mm}$ thick Rogers (R03003C) substrate; overall size of $33.4 \times$ 33.4 squared millimeters. At the optimal resonance frequency of $3.8 \mathrm{GHz}$, simulation results perfectly agree with the standards of UWB antennas, with a high radiation gain and impedance matching status.
\end{abstract}

Keywords

UWB Antennas, Enhanced Gain, FEM, Ansoft HFSS

\section{Introduction}

Printed circuit board (PCB) microstrip antennas belong to the family of Modern antennas; a category that undoubtedly remains very useful in multiple engineering areas such as aircraft, missiles, rockets, spacecraft [1]-[3]; not forgetting commercial areas like mobile satellite communications, global positioning system, Radio Frequency Identification (RFID), Worldwide Interoperability for Microwave Access (WIMAX), Radar Applications, Telemedicine Applications, military systems [4]-[12], etc.

A transmitted signal is UWB if the RL absolute bandwidth exceeds $500 \mathrm{MHz}$ [13] or the fractional bandwidth is more than $20 \%$ at $-10 \mathrm{~dB}$; noting that UWB utilization was authorized by the Federal Communications

${ }^{*}$ Corresponding author.

How to cite this paper: Rushingabigwi, G., Sun, L.G., He, Y.X., Zhu, M.Y., Li, Y.J. and de Dieu Ntawangaheza, J. (2016) The Impact of Substrate Materials to the Design of UWB Modern Antennas. Journal of Computer and Communications, 4, 20-27. http://dx.doi.org/10.4236/jcc.2016.43004 
Commission (FCC) to (3.1 - 10.6) GHz in 2002 [14]. According to [15] [16], printed monopole antennas have many possibilities for UWB performance; thus, the present research focus is put on UWB antennas in theory and practice.

\section{UWB Antennas' State of the Art}

Some UWB signals were emitted by Hertz in 1887 [17], but the year 2002 awakened both academic and industrial research attention that is continually paid on UWB antennas [18]-[20]. Designers of monopole antennas look forward to reducing ground planes. According to the surveyed UWB antenna designs together with the history of UWB antennas, the reality is that UWB antennas existed for a couple of centuries ago [21] [22].

Learning from different authors, our aim now is to furthermore improve on bandwidth and radiation gain performance for PCB's UWB antennas.

\section{The Antenna Geometry, Design Methodology and Discussed Results}

\subsection{Design Structure and Methodology}

A three dimensional solver high frequency simulator structure (HFSS) based on FEM [23] is the software tool selected for the present research. The 3D design model is presented in Figure 1(a). The main parts of the model: antenna as a top layer, ground as a bottom layer and the substrate as a keep-out layer were exported from Ansoft HFSS Modeler and manipulated with the conjunction of Auto CAD (Computer Aided Design) and Altium Designer's Printed Circuit Board environment [24] to produce Figure 1(b), which is useful to manufacture the antenna.

For antenna synthesis, the RL is analyzed by time to time to decide on the necessary bandwidth performance. Analyzed over different substrates, the antenna RL results are two dimensionally exported to Microsoft Excel, as. csv format, later compiled together for comparison purpose. Origin Pro 8 for data analysis and graphing is the software tool utilized to prepare the data for Figure 2.

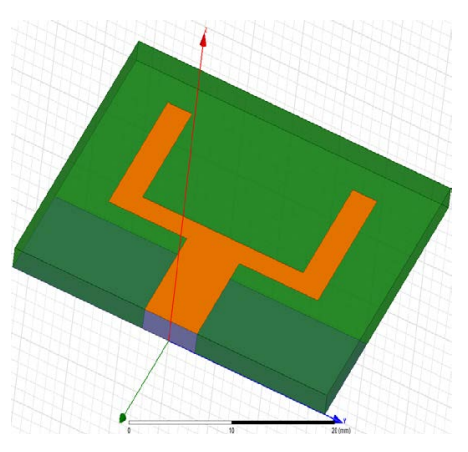

(a)

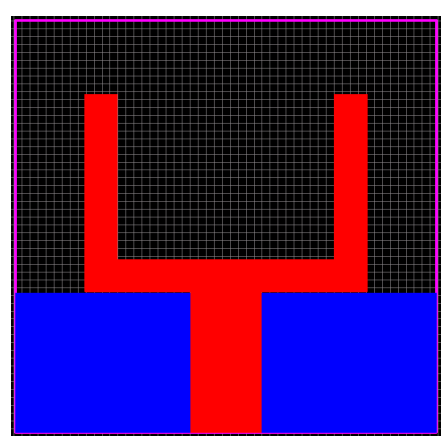

(b)

Figure 1. Design Model's (a) three dimensional view; (b) top view.

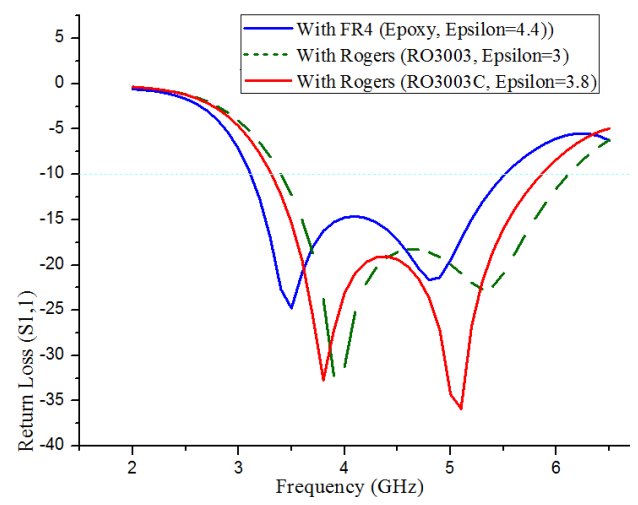

Figure 2. RL with different substrates. 
On RO3003C substrate material, the antenna does not only present optimal fractional bandwidth and radiation gain as detailed in Table 1, but also, the impedance matching with the input feed line is the most competitive for the pre-set frequency of 3.8 GHz. Therefore, all the results presented from Figures 3-8 relate to the antenna simulation on Rogers (ROO3C) substrate. Thus, for this specific research, the selection decision fell on Rogers RO3003C whose dielectric constant is 3.8.

\subsection{The Simulation Results}

\subsubsection{The RL and Voltage Standing Wave Ratio}

According to [25], the RL is the measure of how much of the available power is not delivered to the load. The

Table 1. Antenna bandwidths and gains with different substrates.

\begin{tabular}{cccc}
\hline Substrate & Relative permittivity $\left(\varepsilon_{r}\right)$ & Fractional bandwidth at 3.8 GHz & Radiation Maximum Gain, [dB] \\
\hline Rogers (RO3003) & 3 & $63.2 \%$ & 4.31 \\
Rogers (RO3003C) & 3.8 & $67 \%$ & 4.23 \\
FR4 (Epoxy) & 4.4 & $63.17 \%$ & 3.83 \\
\hline
\end{tabular}

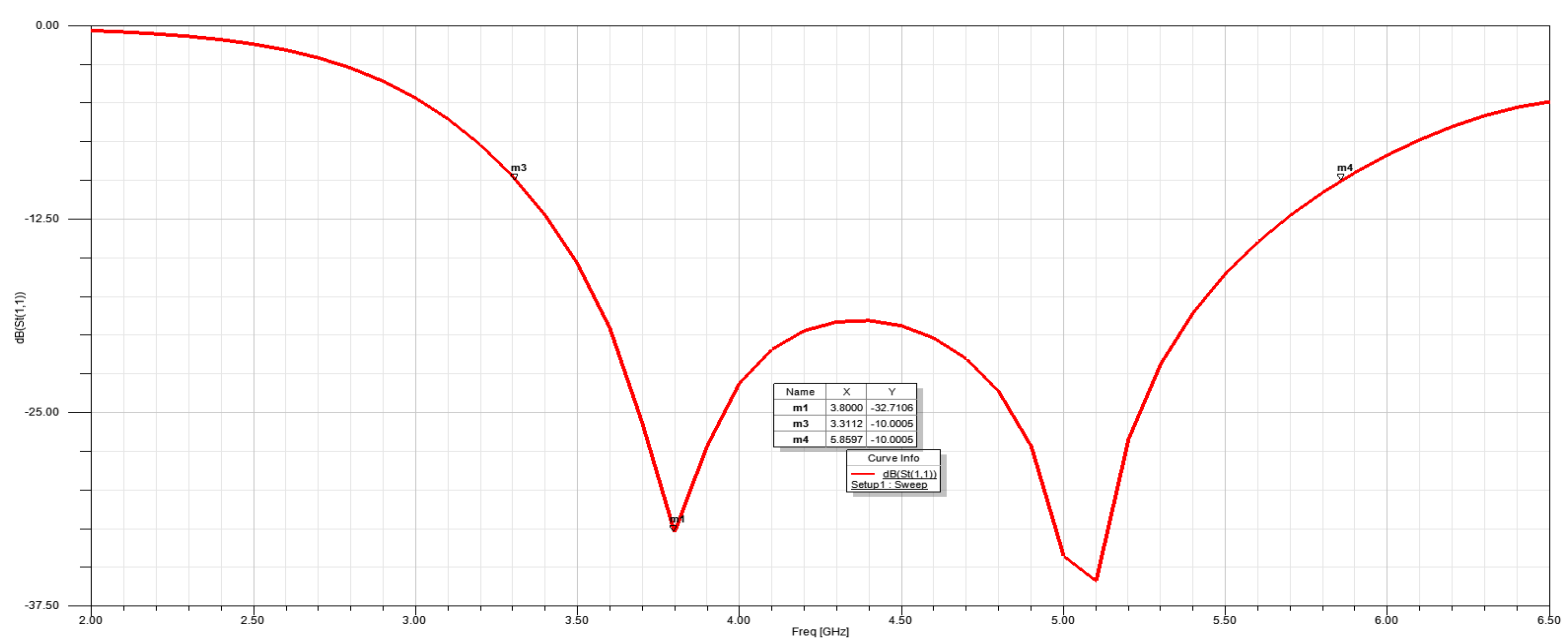

Figure 3. Optimal RL with rogers (RO3003C) substrate.

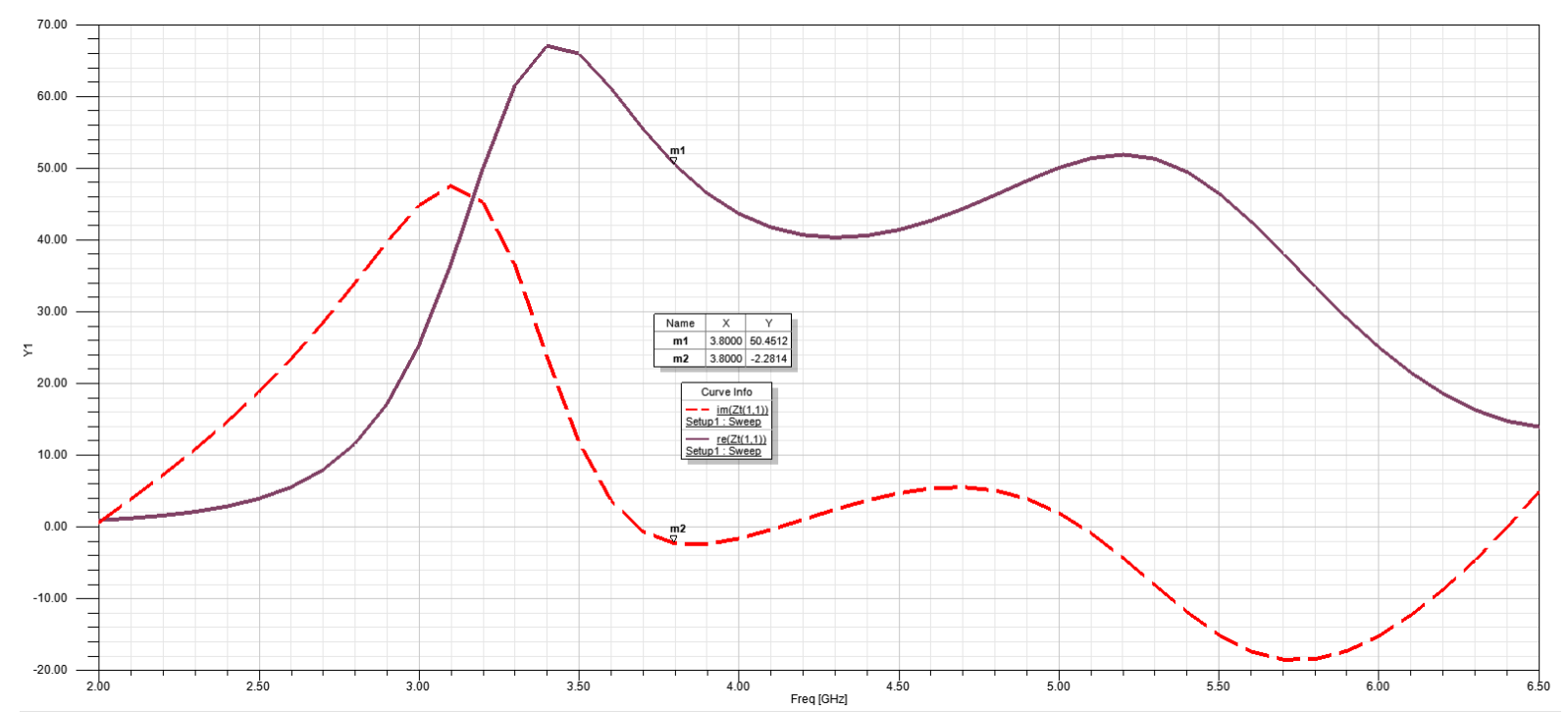

Figure 4. Impedance parameters. 


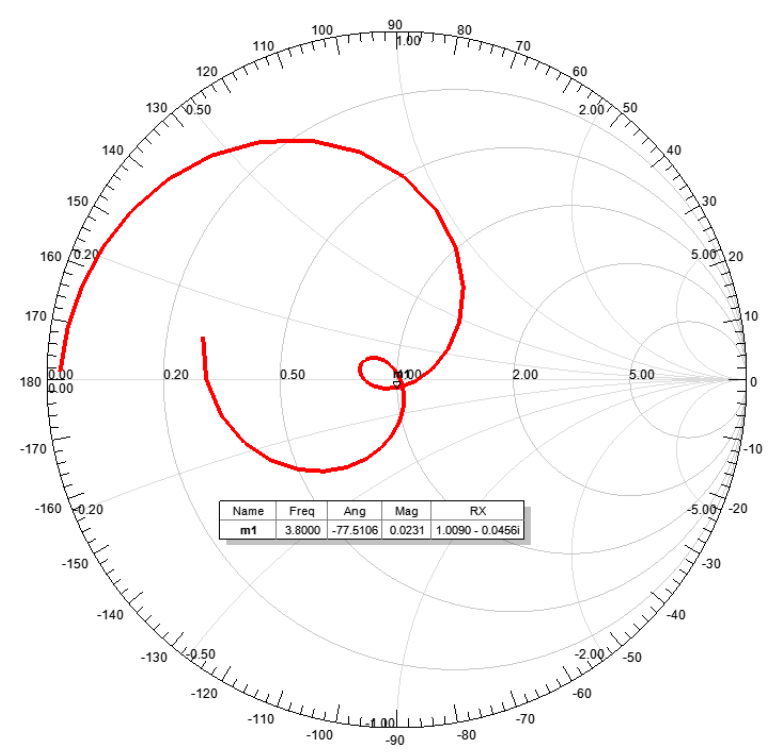

Figure 5. Smith chart.

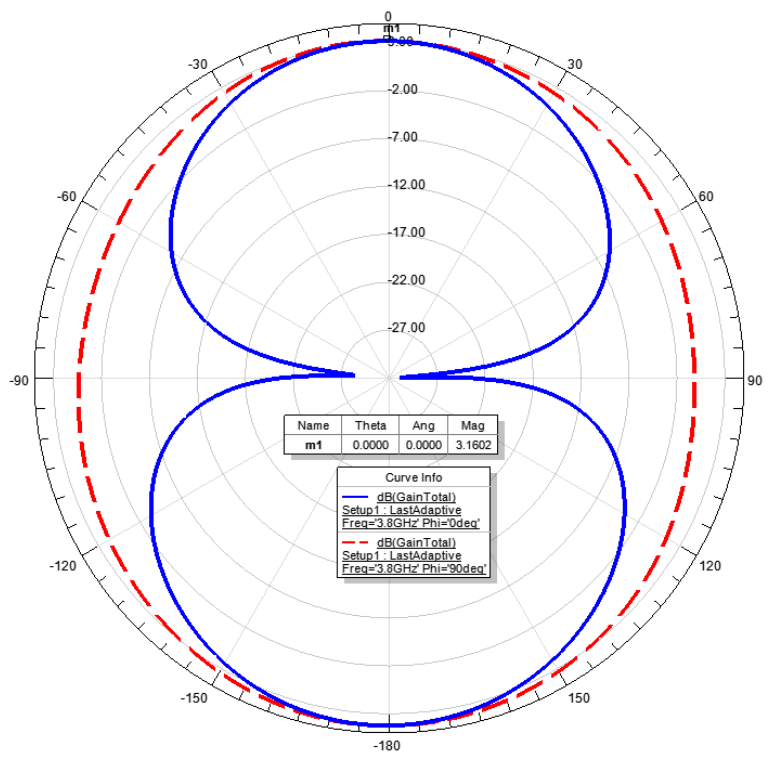

(a)

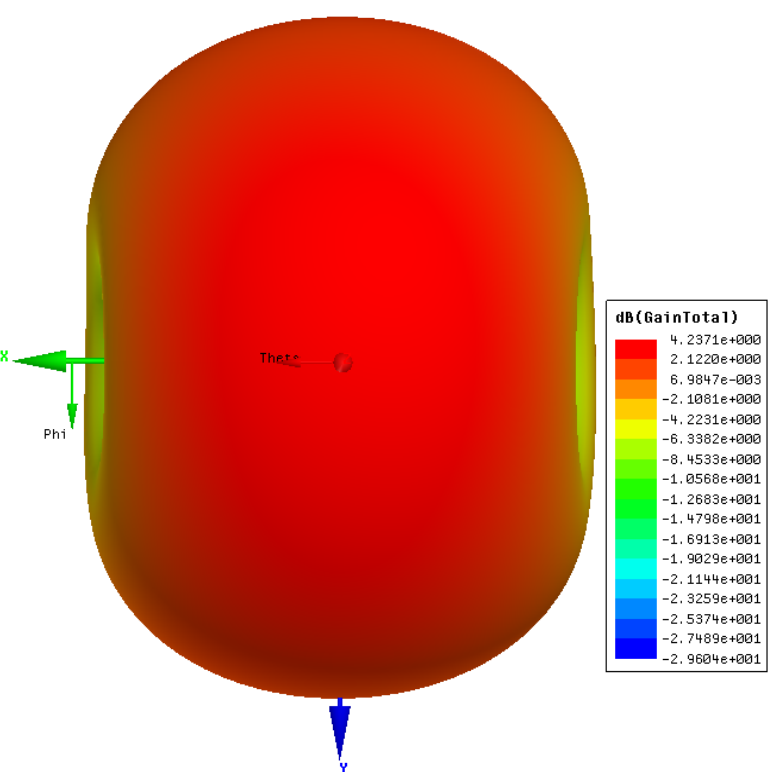

(b)

Figure 6. Radiation power pattern (a) in two dimensional view; (b) in three dimensional view.

reflection coefficient of a totally matched load is zero and its RL is infinity. The comparative RL when the unchanged antenna structure is analyzed over different substrate materials is shown in Figure 2. The optimal RL while the antenna printed over the selected substrate material is shown in Figure 3.

The impedance parameters are measured according to Figure 4; as per the Smith Chart's measurement in Figure 5, the antenna impedance is perfectly matching with the $50 \Omega$ microstrip feed line.

As for the antenna total efficiency $\left(e_{T}\right)$, according to [26], knowing the voltage reflection coefficient at input terminals, $\Gamma$, such that

$$
\Gamma=\frac{Z_{\text {in }}-Z_{0}}{Z_{\text {in }}+Z_{0}}
$$

$Z_{\text {in }}$, the input impedance; 


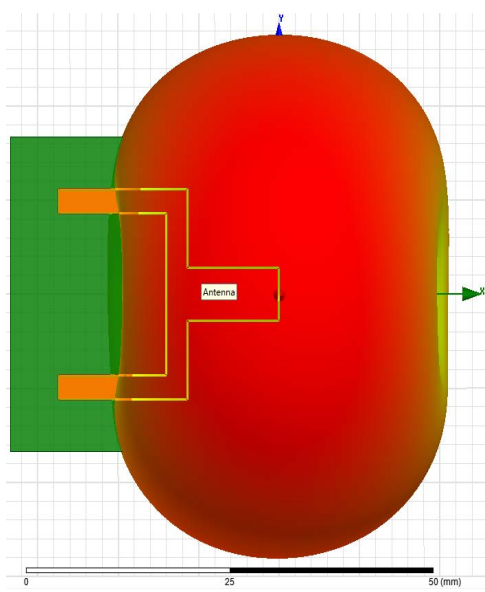

(a)

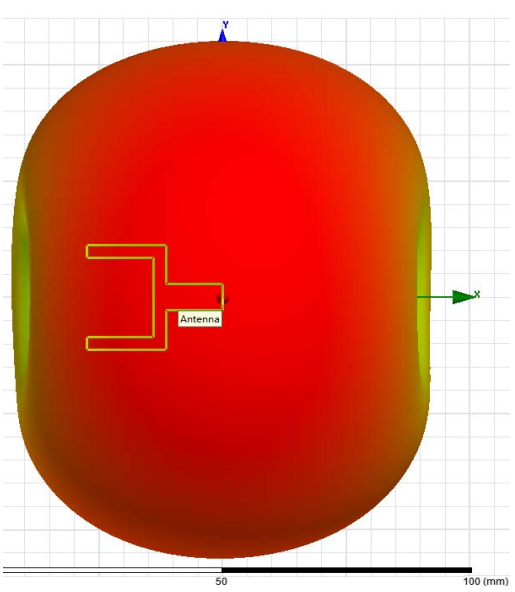

(b)

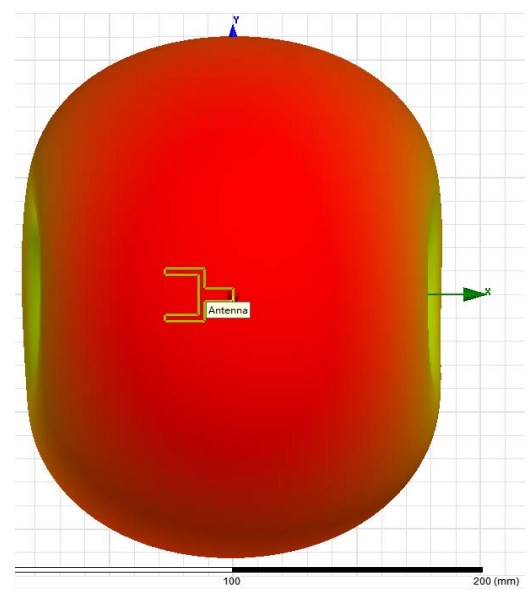

(c)

Figure 7. Radiation fields' overlay (a) 25\%; (b) 50\% overlay; (c) 100\%.

$Z_{0}$, the transmission feed line's characteristic impedance, equals to $50 \Omega$ in normal conditions.

Mathematically, the antenna radiation efficiency is approximately unity since the antenna is simulated under perfect electric conduction (PEC) boundary. So, the computed total antenna efficiency is approximated to the mismatch efficiency; calculations were made possible by the measured impedance parameters in Figure 4. Both the total efficiency and VSWR are now calculated for a resonance frequency of $3.8 \mathrm{GHz}$.

$$
\begin{gathered}
\Gamma_{(3.8 \mathrm{GHz})}=\frac{50.4512-j 2.2814-50}{50.4512-j 2.2814+50}=0.00449-j 0.226=0.023 \angle-78.76^{\circ} \\
e_{T(3.8 \mathrm{GHz})}=1-|\Gamma|^{2}=99.94 \% \\
\operatorname{VSWR}_{(3.8 \mathrm{GHz})}=\frac{1+|\Gamma|}{1-|\Gamma|}=\frac{1+0.023}{1-0.023}=1.023
\end{gathered}
$$

\subsubsection{Radiation Results}

Figure 6 shows both two and three dimensional radiation patterns while Figure 7 and Figure 8 respectively show the radiation fields overlay and the surface currents distribution.

\subsection{Discussions}

With the resonance frequency of either 3.8 GHz or 5.1 GHz, observable from the RL in Figure 3, carefully viewing UWB antenna standards [14]-[16], the microstrip monopole antenna presented in this research paper is undoubtedly a high gain Antenna for UWB receivers and transceivers. It is expected to be an excellent candidate array element for base stations' UWB array antenna; thus, highly boosting the obtained maximum radiation gain of $4.23 \mathrm{~dB}$ furthermore, in comparison with [20].

Application side, this UWB antenna is expected to find applications with Airport search radar, microwave relays, satellite down communications, Studio-To-Transmitter Link (STL) Microwave relays as well as satellite up communications, as illustrated in Figure 9, a summary made according to [27].

Excellent results were obtained by analyzing the antenna on Rogers 3003C, more competitive than on either Rogers 3003 or FR-4 (Epoxy); it has been made clear in Table 1. Optimally, the simulation reached to (3.3 - 5.8) $\mathrm{GHz}$, absolute bandwidth, highly exceeding $500 \mathrm{MHz}$ [13]. The calculated fractional bandwidth is $67 \%$, certainly greater than $20 \%$ [14]. Radiation results indicate the omni-directional radiation; these are very appreciable parameters for UWB Antennas in general.

\section{Conclusions}

The pre-set goals to review and present the state of the art in UWB antenna has been successfully strengthened 


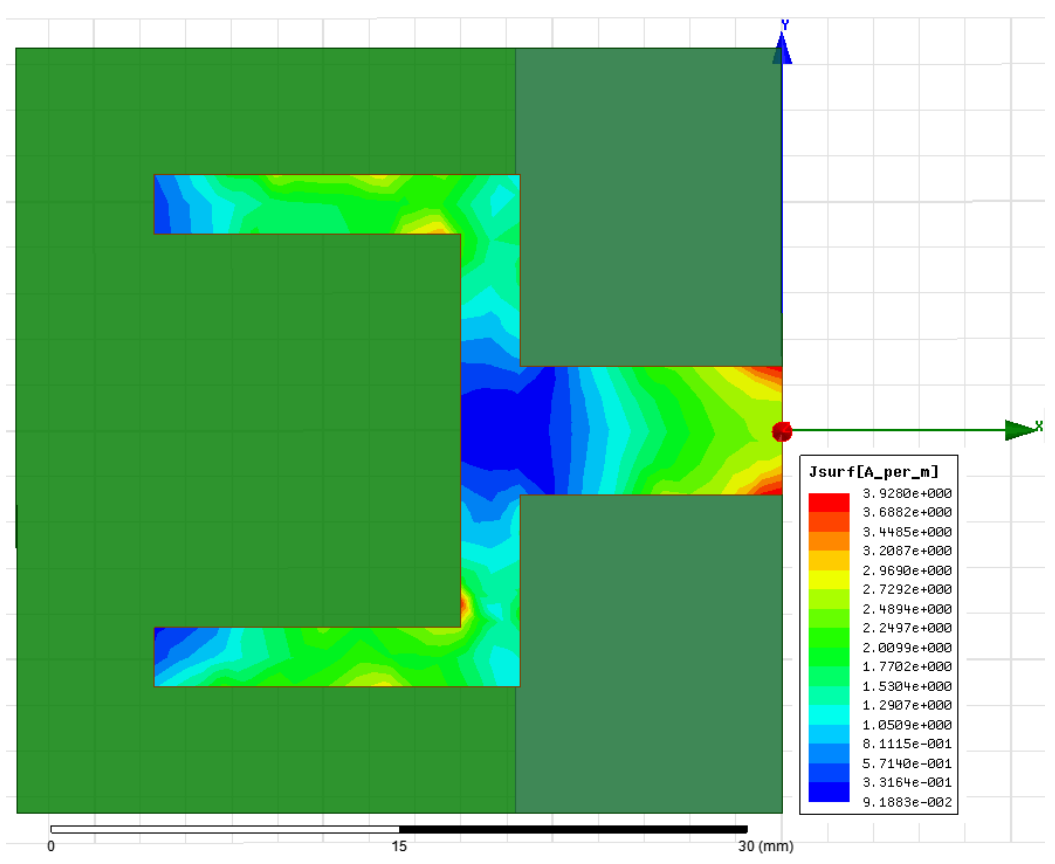

Figure 8. Magnitude surface current density.

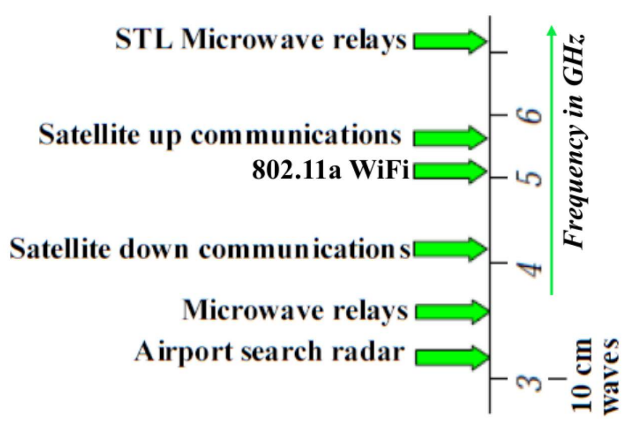

Figure 9. The antenna's applications in the microwave spectrum.

by simulation results, presented here in this research article.

For the well conducted simulation, repeatedly yielding the same results, manufacturing results must certainly match with the simulation results.

We are in the process of manufacturing this antenna; it will then be tested and its measured results will be compared to simulation results. Our antenna prototype will undergo several modifications in order to finally hit the target furthermore.

\section{Acknowledgements}

A lot of gratitude is addressed to the Government of People's Republic of China, to have supported and strengthened engineering research activities in the University of Science and Technology of China (USTC). Many thanks also go to the University of Rwanda, college of Science and Technology (UR, CST) for a couple of valuable supports.

\section{References}

[1] Da, G.F. (2006) Microstrip Patch Antennas. In: Fang, D.G., Eds., Antenna Theory and Microstrip Antennas, Science Press, Beijing, Chapter 3, 111-145.

[2] Constantine, A.B. (2008) Microstrip Antennas: Analysis, Design and Application. In: Constantine, A.B., Ed., Modern 
Antenna Handbook, John Wiley \& Sons, Inc., USA, Chapter 4, 157-200.

[3] Constantine, A.B. (2005) Microstrip Antennas. In: Antenna Theory Analysis and Design, 3rd Edition, John Wiley \& Sons, Inc., Publication, Chapter 14, 811-879.

[4] Lelaratne, R. and Langley, R.J. (2000) Dual-Band Patch Antenna for Mobile Satellite Systems. IEEE Proceedings on Microwaves, Antennas and Propagation, 147, 427-430. http://dx.doi.org/10.1049/ip-map:20000864

[5] Khondaker, R.M.H., Ahmed, S.S., Imran, K.M. and Nishat, S. (2014) Design of a Triple Band Microstrip Patch Antenna for Cellular and Wi-Fi Application. International Conference on Informatics, Electronics \& Vision (ICIEV), Dhaka, 23-24 May 2014, 1-6. http://dx.doi.org/10.1109/ICIEV.2014.6850839

[6] Patel, S.K. and Kosta, Y.P. (2011) E-Shape Microstrip Patch Antenna Design for GPS Application. IEEE Nirma University International Conference on Engineering (NUiCONE), Ahmedabad, 8-10 December 2011, 1-4. http://dx.doi.org/10.1109/NUiConE.2011.6153261

[7] Ibrahim, R.A.R., Yagoub, M.C.E. and Habash, R.W.Y. (2009) Microstrip Patch Antenna for RFID Applications. IEEE Canadian Conference on Electrical and Computer Engineering, St. John’s, NL, 3-6 May 2009, 940-943. http://dx.doi.org/10.1109/CCECE.2009.5090266

[8] Mokhtar, M.H., Rahim, M.K.A., Murad, N.A. and Majid H.A. (2013) A Compact Slotted Microstrip Patch Antenna for RFID Applications. IEEE International Conference on RFID Technologies and Applications (RFID-TA), Johor Bahru, 4-5 September 2013, 1-4. http://dx.doi.org/10.1109/RFID-TA.2013.6694536

[9] Dwivedi, S., Rawat, A. and Yadav, R.N. (2013) Design of U-Shape Microstrip Patch Antenna for WiMAX Applications at $2.5 \mathrm{GHz}$. IEEE Tenth International Conference on Wireless and Optical Communications Networks (WOCN), Bhopal, 26-28 July 2013, 1-5. http://dx.doi.org/10.1109/WOCN.2013.6616214

[10] Amit, S.B. and Mithilesh, K. (2014) Microstrip Patch Antenna for Radiolocation using DGS with Improved Gain and Bandwidth. IEEE International Conference on Advances in Engineering \& Technology Research (ICAETR), Unnao, 1-2 Aug. 2014, 1-5. http://dx.doi.org/10.1109/ICAETR.2014.7012873

[11] Khaleel, H.R., Al-Rizzo, H.M., Rucker, D.G. and Elwi, T.A. (2010) Wearable Yagi Microstrip Antenna for Telemedicine Applications. IEEE Radio and Wireless Symposium, New Orleans, 10-14 January 2010, 280-283. http://dx.doi.org/10.1109/RWS.2010.5434177

[12] Ramasamyraja, R., Pandiguru, M., Arun, V. (2014) Design of Ultra Wide Band Antenna for Tactical Communication in Electronic Warfare. IEEE International Conference on Communication and Signal Processing (ICCSP), Melmaruvathur, 3-5 April 2014, 1256-1259. http://dx.doi.org/10.1109/ICCSP.2014.6950052

[13] Tatsis, G., Raptis, V. and Kostarakis, P. (2010) Design and Measurements of Ultra-Wideband Antenna. International Journal of Communications, Network and System Sciences, 3, 116-118. http://dx.doi.org/10.4236/ijcns.2010.32017

[14] Yang, L. and Giannakis, G.B. (2004) Ultra-Wideband Communications. IEEE Signal Processing Magazine, 26-54.

[15] Lak, H.J., Ghobadi, C. and Nourinia, J. (2011) A Novel Ultra-Wideband Monopole Antenna with Band-Stop Characteristic. Wireless Engineering and Technology, 2, 235-239. http://dx.doi.org/10.4236/wet.2011.24032

[16] Bakariya, P.S. and Dwari, S. (2012) A Compact Super Ultra-Wideband (UWB) Printed Monopole Antenna. Proceedings of IEEE 5th International Conference on Computer and Devices for Communication (CODEC), Kolkata, 17-19 December 2012, 1-3. http://dx.doi.org/10.1109/codec.2012.6509206

[17] Moe, Z.W., Davide, D., Andreas, F.M., Werner, W. and Jinyun, Z. (2009) History and Applications of UWB. Proceedings of the IEEE, 97, 198-204.

[18] ZhiNing, C., Max, J.A., Xianming, Q., Xuan, H.W., Terence, S.P.S. and Ailian, C. Planar Antennas. IEEE Microwave Magazine, 6, 63-73.

[19] Chang, F.-S., Lin, C.-Y., Chen, H.-T. and Chao, K.-C. (2005) A Novel Monopole Antenna Backed by a U-shaped Ground Plane for Multi-B and WLAN Application. IEEE International Workshop on Antenna Technology Small Antennas and Novel Metamaterials (IEEE iWAT2005), 7-9 March 2005, 517-520. http://dx.doi.org/10.1109/iwat.2005.1461130

[20] Wang, Z.D., Zhang, G.X., Yin, Y.Z. and Wu, J.J. (2014) Design of a Dual-Band High-Gain Antenna Array for WLAN and WiMAX Base Station. IEEE Antennas and Wireless Propagation Letters, 13, 1721-1724. http://dx.doi.org/10.1109/LAWP.2014.2352618

[21] Hans, G.S. (2012) Three Centuries of UWB Antenna Development. IEEE International Conference on Ultra-Wideband (ICUWB), 506-512.

[22] Hans, G.S. (2004) A Brief History of UWB Antennas. IEEE Aerospace and Electronic Systems Magazine, 19, 22-26. http://dx.doi.org/10.1109/MAES.2004.1301770

[23] Mingyang, L. and Liu, M. (2014) Monopole Antenna and Dipole Antenna Design. In: Mingyang, L. and Liu, M., Eds., HFSS Antenna Design, 2nd Edition, Publishing House of Electronics Industry, Beijing, Chapter 3, 22-80. 
[24] Xuefei, G., Yongli, A. and Jian, L. (2014) Principles of PCB Design. In: Xuefei, G., Yongli, A. and Jian, L., Eds., Altium Designer 10. Schematic Diagram and PCB Design Course, Beijing Hope Electronic Press, Beijing, Chapter 4, 69-95.

[25] Steer, M. (2010) Transmission Lines. Microwave and RF Design. In: Steer, M., Ed., A System Approach, SciTech Publishing, Raleigh, Chapter 4, 196-197.

[26] Balanis, C.A. (2005) Fundamental Parameters of Antennas (Antenna Efficiency). In: Balanis, C.A., Ed., Antenna Theory Analysis and Design, 3rd Edition, A John Wiley \& Sons, Inc., Publication, Chapter 2, pp. 64-66

[27] Min, J. and Shi-Lin, X. (2013) Design Principles and Applications of a Novel Electromagnetic Spectrum Table. IEEE Proceedings of the International Symposium on Antennas \& Propagation (ISAP), Nanjing, 23-25 October 2013, 01, 184-187. 